\title{
SUBALTERN DALAM NOVEL AROK DEDES KARYA PRAMOEDYA ANANTA TOER: KAJIAN POSKOLONIAL GAYATRI SPIVAK
}

\section{SUBALTERN IN AROK DEDES NOVEL WRITEN BY PRAMOEDYA ANANTA TOER: POST COLONIAL STUDY OF GAYATRI SPIVAK}

\author{
Arisni Kholifatu ${ }^{*}$, Tengsoe Tjahjono ${ }^{2}$ \\ Pendidikan Bahasa dan Sastra, Pascasarjana Universitas Negeri Surabaya, \\ Indonesia $^{1,2}$

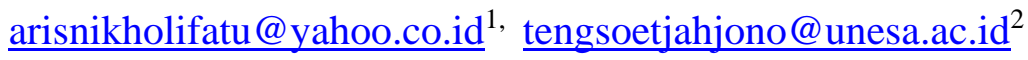 \\ *penulis korespondensi
}

\begin{tabular}{ll}
\hline Info Artikel & ABSTRAK \\
\hline Sejarah artikel: & Tujuan penelitian ini mendeskripsikan pengaruh tahta tertinggi dan \\
Diterima: & perlawanan kaum subaltern pada novel Arok Dedes karya Pramoedya \\
8 November 2019 & Ananta Toer dengan menggunakan teori postkolonialisme Gayatri Spivak. \\
Direvisi: & Penelitian ini merupakan jenis penelitian deskriptif kualitatif. Pendekatan \\
12 November 2019 & dalam penelitian ini mengunakan pendekatan kualitatif karena dalam \\
Disetujui: & penelitian ini menggunakan sumber data novel Arok Dedes yang berkisah \\
20 Januari 2020 & tentang kudeta di Tanah Jawa. Data penelitian ini adalah kata, kalimat, \\
& paragraf, yang terdapat dalam novel Arok Dedes karya Pramoedya Ananta \\
Kata kunci: & Toer dengan menggunakan teori poskolonial Ggayatri Spivak. Teknik \\
Subaltern, poskolonial,, & pengumpulan data dalam penelitian ini menggunakan metode dokumentasi \\
pengaruh tahta, & atau pustaka. Teknik analisis data penelitian ini menggunakan teknik \\
perlawanan & analisia deskriptif. Hasil dari penelitian adalah pengaruh tahta tertinggi dan \\
& perlawanan kaum subaltern pada novel Arok Dedes karya Pramoedya \\
& Ananta Toer.
\end{tabular}

\begin{tabular}{|c|c|}
\hline Article Info & ABSTRACT \\
\hline Article history: & The purpose of this study is to describe the influence of the highest throne \\
\hline Received: & and the resistance of the subalterns on the novel Arok Dedes by Pramoedya \\
\hline 8 November 2019 & Ananta Toer by using the postcolonialism theory of Gayatri Spivak. This \\
\hline Revised: & research is a descriptive qualitative research. The approach in this study \\
\hline 12 November 2019 & using a qualitative approach because in this study used Arok Dedes story \\
\hline Accepted: & novel as data sources which is about a coup in Java. This research data is \\
\hline 20 January 2020 & words, sentences, paragraphs, contained in Arok Dedes novel by Pramoedya \\
\hline Keywords: & $\begin{array}{l}\text { Anan ta Toer by using postcolonial Ggayatri Spivak theory. Data collection } \\
\text { techniques in this study used the method of documentation or literature. The }\end{array}$ \\
\hline Subaltern, postcolonial, & data analysis technique of this study used descriptive analysis \\
\hline $\begin{array}{l}\text { influence of throne, } \\
\text { resistance }\end{array}$ & $\begin{array}{l}\text { techniques. The results of the study are the influence of the highest throne } \\
\text { and the resistance of the subalterns on the novel Arok Dedes by Pramoedya } \\
\text { Ananta Toer. }\end{array}$ \\
\hline
\end{tabular}

\section{PENDAHULUAN}

Novel merupakan salah satu karya sastra yang dapat dijadikan media pengarang untuk memberikan gambaran realistis melalui unsur-unsur pengembangnya, seperti tokoh, alur, dan latar yang tercipta dari sudut pandang pengarang dengan menggunakan bahasanya. Novel memungkinkan untuk merekam seluruh 
perkembangan itu secara utuh dan menyeluruh. Selain itu, novel lebih leluasa mengeksplorasi detail-detail peristiwa, suasana, dan karakter tokoh untuk menghidupkan cerita. Keutuhan sebuah novel tidak ditopang oleh kepadatan cerita seperti cerpen, namun ditopang oleh tema karyanya (Najid, 2009:23).

Arok Dedes adalah sebuah novel politik yang komplek dengan latar pedalaman sejarah kerajaan Jawa. Berkisah tentang kudeta pertama di Nusantara. Kudeta ala Jawa. Kudeta licik tapi cerdik. Berdarah tapi pembunuh sejatinya bertepuk dada menikmati penghormatan yang tinggi. Melibatkan gerakan militer (Gerakan Gandring), menyebarkan syak wasangka dari dalam, memperhadapkan antarkawan, dan memanasi perkubuan. Aktor-aktornya bekerja seperti hantu. Kalaupun gerakannya diketahui, namun tiada bbukti yang paling sahih bagi penguasa untuk menyingkirkannya.

Arok adalah simpul dari gabungan antara mesin paramiliter kelicikan politis sipil yang cerdik-rakus (dari kalangan sudra/agrari yang merangkakkan nasib menjadi penguasa tunggal tanah Jawa). Arok tak mesti memperlihatkan tangannya yang berlumur darah mengiringi kejatuhan Ametung di Bilik Agung Tumapel, karena politik tak selalu identik dengan perang terbuka.

Politik adalah permainan catur di atas papan bidak yang utuh kejelian, ketegangan melempar umpan-umpan untuk mendapatkan peruntungan besar. Tak ada kawan dan lawan. Yang ada hanya tahta di mana seluruh hasrat bisa diletupkan sejadi-jadi yang dimau. Pada akhirnya novel Arok Dedes menggambarkan peta kudeta politik yang kompleks yang "disumbang"
Jawa untuk Indonesia. Sekaligus dengan bentuk praktik di lapangan, seperti: perbudakan, pendudukan, pemindahan penduduk, pemaksaan bahasa, dan berbagai bentuk invasi kultural yang lain. Meskipun demikian, keberagaman permasalahan seperti di atas dipersatukan oleh tema yang sama, yaitu kolonialisme (Ratna,2008)

Latar belakang Arok adalah seorang sudra yang tidak jelas asal usulnya yang menjelma menjadi seorang Ksatria dan Brahmana sekaligus. Arok juga merupakan perpaduan yang unik antara penganut Shiwa, Wisnu, dan Budha karena dalam perjalanan hidupnya dia belajar dari beberapa guru yang berbeda keyakinan.

Keterlibatan kaum beragama dalam perebutan kekuasaan juga diulas dengan halus dan mengalir dalam cerita ini. Keberadaan Belakangka sebagai wakil Kerajaan Kediri Pakuwuan Tumapel menunjukkan ambisi dan pengaruh kaum bangsawan. Restu dari kaum Brahmana yang didapat Arok dalam menggulingkan sang akuwu, serta kehidupan keseharian para Brahmana adalah bukti bagaimana kearifan sekaligus ambisi kaum agama diperlihatkan. Pola komunikasi antar kasta yang sangat diskriminatif bahkan terlihat sejak dari panggilan (seperti Yang Mulia, Yang Suci). Belum lagi perlakuan terhadap kaum sudra, ironi kehidupan para budak yang dikenal lewat tapas di kepala, sampai pada nasib jejaro-jejaro yang harus dipotong lidahnya demi menjaga rahasia. Msih banyak lagi fakta-akta miris berkaitan dengan feodalisme jawa diperlihatkan, kebiasaaan yang sampai saat ini masih jadi kebanggaan bagi sebagaian orang.

Kaum strata yang tinggi memiliki kekuasaan sehingga bisa melakukan semena-mena terhadap kaum strata rendah. Hal ini 
memunculkan kelompok-kelompok yang berupaya melakukan perlawanan agar setara dengan Ksatria dan Brahmana. Kaum inilah yang kemudian disebut kaum subaltern.

Kaum subaltern menurut teori Gayatri Spivak bahwa dalam sistem masyarakat terdapat tingkatantingkatan. Tingkatan-tingkatan tersebut muncul istilah masyarakat kelas bawah atu yang disebut msyarakat subaltern. Masyarakat subaltern adalah masyarakat kelas bawah yang tidak mendapat perhatian dari pemerintah kolonial (kaum Kstaria dan Brahmana) juga masyarakat yang beradda pada tiingkat inferior. Namun masyarakat sublatern mempunyai daya untuk menyamai masyarakat kelas atas. Caracara yang digunakan oleh kaum subaltern dalam rangka memperoleh pengakuan dan penghargaan masyarakat kelas atas inilah yang menjadin objek kajian Spivak.

Penelitian-penelitian terdahulu yang relevan dengan novel Arok Dedes karya Pramoedya Ananta Tour dan kajian poskolonial Gayatri Spivak yaitu jurnal oleh Saputri (2019), hasil dari penelitiannya menuliskan adanya dominasi penjajah terhadap subaltern dalam bentuk penindasan dan kekuasaan, yang dimiliki Bangsa Belanda yang memegang peran superior. Pengaruh dominasi penjajah terhadap subaltern dalam bentuk segi fisik dan batin (mental) yang mengakibatkan perubahan fisik dan melemahnya mental, menimbulkan ketakutan, paranoid dan rasa dendam oleh subaltern. bentuk perlawanan subaltern terhadap para penjajah dengan bentuk cacian, pemberontakan dan pertempuran.

Selain itu, jurnal Bahardur (2016). Hasil penelitian menunjukkan bahwa tokoh-tokoh prib umi, khususnya perempua menjadi subaltern karena dimarginalisasi, dimiskinkan secara ekonomi, mendapat pelabelan, serta mengalami pelecehan seksual.

Penelitian yang relevan poskolonial kajian subaltern adalah penelitian yang dilakukan oleh Wiwik Hidayati, skripsi (2008) penulis menganalisis pengaruh penjajahan dengan menemukan data bahwa penjajahan Belanda maupun Jepang sama-sama menimbulkan kesengsaraan bagi orang-orang yang terjajah, yaitu masyarakat Indonesia. Kerugian yang didapatkan tidak hanya menyangkut materi semata. Namun juga dari segi yang lain yakni dari segi mental, pola pikir, dan budaya.

Berbeda dengan penelitian sebelumnya, penelitian ini difokuskan pada: 1) Pengaruh tahta tertinggi terhadap kaum subaltern pada novel Arok Dedes karya Pramoedya Ananta Toer, dan 2) Perlawanan terhadap kaum subaltern pada novel Arok Dedes karya Pramoedya Ananta Toer.

Melalui penelitian ini, penulis ingin mencapai beberapa tujuan akademis yang diharapkan mampu mengakomodasi ilmu pengetahuan di dunia sastra. Pertama, menambah ferensi kajian tentang sublatren Gayatri Spivak yang terefleksi dalam karya sastra. Kedua, penelitian inin diharapkan mampu menemukan bentuk lain dari sublatern yag ada di dalam novel Arok Dedes karya Pramoedya Ananta Toer. Ketiga, peneliti memberikan sumbangan terhadap pembaca; memperkenalkan cara baca subaltern sebagai kajian sastra yang tidak berhenti pada deskripsi perjuangan kelompok marginal saja.

Terakhir, diharapkan penelitian ini dapat memberikan sumbangan terhadap kritik sastra di Indonesia terutama dalam ranah subaltern dan 
dapat digunakan untuk membantu pemerintah dalam membuat kebijakan dalam membuat kebijakan terkait upaya menghadapi dampak kolonoliasme yang masih berkembang sampai saat ini dalam masyarakat Indonesia.

\section{METODE}

Penelitian ini merupakan penelitian kualitatif. Melalui rancangan yang digunakan tersebut, penelitian dapat ditentukan kebenaran atau kesalahan penjelasan mengenai fakta yang dijadikan objek sasaran. Menurut Marshall dan Rossman (2006:3), penelitian kualitatif adalah penelitan yang bersifat natural, data deskriptif, mementingkan proses, bersifat induktif, menggunakan multimetode, terfokus pada konteks, dan mementingkan interpretasi dalam rangka menemukan makna. penelitian kualitatif merupakan salah satu jenis penelitian yang hasil temuannya tidak diperoleh dari hasil hitungan.

Penggunaan metode kualitatif ini dengan beberapa alasan sebagai berikut: (1) data penelitian sastra tidak mengunakan angka-angka, sehingga tepat apabila menggunakan rancangan penelitian kualitatif, (2) data penelitian ini berupa data deskriptif sesuai fokus penelitian.penelitian, (3) peneliti bertindak sebagai instrumen penelitian, (4) penelitian ini lebih mengutakan proses dan produk, dan (5) penelitian ini lebih menekankan pada pendeskripsian makna data karena pada dasarnya penelitian kualitatif lebih menekankan pada makna data.

Sumber data penelitian ini adalah novel Arok Dedes karya Pramoedya Ananta Toer. Data penelitian ini mencakup data deskriptif yang ada dalam tulissan novel Arok Dedes karya Pramoedya Ananta Toer yaitu berupa kata, kalimat, paragraf, yang kemudian dianalisis sesuai dengan kebutuhan penelitian yaitu data yang berkaitan dengan pengaruh tahta tertinggi dan perlawanan kaum subaltern.

Teknik pengumpulan data dalam penelitian ini menggunakan teknik baca dan catat. Analisis data dilakukan dengan analisis isi (content anakysus) dengan cara mencari dan menganalisis isi novel Arok Dedes karya Pramoedya Ananta Toer. Selanjutnya dilakukan penafsiran pengaruh tahta tertinggi dan perlawanan kaum subaltern.

Adapun prosedur atau langkah-langkah analisis data penelitian ini adalah sebagai berikut.

(1) Peneliti mengidentifikasi data pada novel Arok Dedes karya Pramoedya Ananta Toer, untuk memudahkan dalam menganalisis serta menelusuri koherensi antara sumber data dengan usulan atau penjabaran maka peneliti menggunakan pengodean dalam penelitiannya.

Contoh:

"Tak ada yang bisa bantah Sri Erlangga seorang pembangun besar. Satu yang pada waktunya akan Bapa Mahaguru katakan". (AD: 65)

Keterangan : AD : Arok Dedes

65: Halaman

(2) Peneliti menganalisis data yang telah diidentifikasi sebelumnya dengan menggunakan konsep Gayatri Spivak yang telah dipilih oleh peneliti.

(3) Penarikan kesimpulan. Pada tahap ini merupakan kelanjutan dari penyajian ddan ahsil analisis yang 
disimpulkan secara rinci dari hasil penelitian tersebut.

\section{HASIL DAN PEMBAHASAN}

Bagian hasil ini peneliti menguraikan hasil penelitian dan pembahasan terhadap Subaltern pada novel Arok Dedes karya Pramoedya Ananta Toer dengan menggunakan kajian poskolonial Gayatri Spivak, yakni terdiri dari bagian pertama, penyajian hasil analisis data tentang pengaruh tahta tertinggi terhadap subaltern. Kedua, perlawanan kaum subaltern.

\section{Pengaruh Tahta Tertinggi terhadap} Subaltern pada Novel Arok Dedes Karya Paramoedya Ananta Toer

Penggambaran tokoh kaum tahta tertinggi terhadap kaum sublaterrn dalm novel Arok Dedes (AD) di sini pertama bisa dijumpai pada tokoh Arya Artya, seorang brahmana. Kaum brahmana adalah kaum dai golongan cendikiawan dan pemimpin agama. Namun karena berasal dari kaum brahmana tersebut, Arya Artya memanfaatkan stratanya untuk memperkaya dirinya sendiri. Hal tersebut terbukti di dalam kutipan novel sebagai berikut.

"Sesuatu telah ditemukannya untuk menciptakan perbudakan. Akuwu Tumapel menyokong dan memanfaatkannya. Dan dipergunakan budak-budak itu untuk memperkaya diri mereka berdua." (AD:34-35)

Hal itu sejalan dengan pemikiran Spivak bahwa kaum subaltern di sini adalah budak atau rakyat lemah tidak bisa melawan atas perintah kaum strata yang lebih tinggi yaitu di sini adalah Brahmana.
"Tak ada yang bisa bantah Sri Erlangga seorang pembangun besar. Satu yang pada waktunya akan Bapa Mahaguru katakan. " (AD: 65)

Dalam kutipan di atas Sri Erlangga sebagai raja yang tidak bisa membantah perintahnya. Karena dia adalah seorang raja apa pun perintahnya harus dilaksanakan khusunya buat rakyat. Hal tersbut membuktikan penguasa seorang raja untuk melakukan kehendaknya terrutama dengan rakyat atau kaum lemah.

Seperti yang dikemukakan oleh Foucault (2009:122), bahwa kekuasaan bukan sesuatu yang diperoleh, dirampas atau dibagi, sesuatu yang digenggam atau jumlahnya, dan dalam permainan hubungan yang tak sederajat dan bergerak.

\section{Perlawanan Kaum Subaltern pada Novel Arok Dedes Karya Pramoedya Ananta Toer}

Spivak menunjukkan

ketegangan antara penapat beberapa sejarawan subaltern untuk menawarkan pemikiran strukturalis mengenai pemberrontakan, yang membahas cara pembrontakan subaltern. Spivak mengemukakan bahwa kaum subaltern yang memberontak dan melawan dominasi penguasa. Beradasarkan hal tersebut dibutuhkan kaum elit dalam membangtu dan bertindak secara nyata untuk memperjangkan kelompok subaltern tersebut. novel Arok Dedes (AD) menceritakan bagiamana kelompok subaltern yang ditindas namun memiliki cara yang cerdas untuk melakukan perlawanan. Perlawanan di sini adalah kuddeta terhadap Tunggal Ametung. Novel Arok adalah lelaki yang cerdas. Dia bisa sangat mudah 
menangkap segala ilmu yang diberikan oleh Dang Hyang Lohgawe. Hal tersebut tampak pada kutipan berikut.

"Sudah lama aku timbangtimbang. Kau seorang pemuda yang cerdas, giat, gesit, ingatanmu sangat baik, berani, tabah menghadapi segalanya. Aku tidak tahu apakah yang kau perbuat selama tumbuh dari hatimu yang suci dan pertimbanganmu yang masak". (AD: 60)

Pada kutipan di atas menjelaskan bahwa Arok adalah lelaki yang cerdik. Dengan sikapnya yang seperti itu menunjukkan bahwa dia bisa menjadi lelaki yang tidak lemah dan perpegang teguh. Sikap tersebut bisa menjadikan dia menjaddi kuat dan bisa melawan kekuasan TunggalAmetung. Novel Arok Dedes mencerritakan Mahaguru Dang Hyang Lohgawe dan Ken Arok tidak suka pada Penngusa. Hal tersebut dapat dilihat dalam kutipan sebagai beikut.

"Bapa Mahaguru Dang Hyang Lohgawe tidak suka pada Sri Baginda Kretajaya, apalagi pada akuwunya di Tumapel, Tunggal Ametung. Bapa percaya pada kami, maka juga percaya persekutuan gelap dan jahat tiada bakal dituduhkan pada kami semua ini. Bapa Mahaguru Ddang Hyang Lohgawe menimbang kami semua suddah dewasa untuk bergabung dalam persekutuan para brahmana, menundukkan kembali Hyang Mahadewa Syiwa pada Cakrawartinya. Apuni sahaya, ya, Bapa Mahaguru". (AD: 64)
Pada kutipan di atas menjelaskan bahwa hal-hal yang dilakukan oeh kaum sublatern terhadap penguasa memiliki cara tersendiri. Di dalam novel AD tersebut Ken Arok menjadi brahmana agar mudah memberontak terhadap penguasa.

Konsep pemikiran Spivak mengenai kaum subaltern bahwa mereka adalah kaum yang inferior, tiddak berdaya, dan suara mereka tidak dapat didengar. Namun, dalam novel ini ada perlawanan yang dilakukan oleh Arok terhadap Tunggal Ametung.

\section{SIMPULAN}

Berdasarkan hasil analisis data dan pembahasan subaltern pada pada novel Arok Dedes karya Pramoedya Ananta Toer kajian : Poskolonial Gayatri Spivak dapat disimpulkan sebagai brikut.

Pertama, Pengaruh tahta tertinggi dalam subaltern dalam novel Arok Dedes karya Pramoedya Ananta Toer dilakukan oleh Kasta Ksatria dan Brahmana yaitu okeh Tunggal Ametung.

Kedua, perlawanan kaum subaltern yang dilakukan Arok Dedes terhadap Tunggal Ametung dengan meningkatnya dia dari kaum sudra menjadi kaum satria dan brahmana untuk memulihkan tata jagad Pramudita.

Selanjutnya penelitian ini diharapkan dapat memberikan sumbangan terhadap kritik sastra di Indonesia terutama dalam ranah subaltern dan dapat digunakan untuk membantu pemerintah dalam membuat kebijakan dalam membuat kebijakan terkait upaya menghadapi dampak kolonoliasme yang masih berkembang sampai saat ini dalam masyarakat Indonesia. 


\section{DAFTAR PUSTAKA}

Bahardur, Iswadi, (2016). Pribumi Subaltern dalam Novel-novel Indonesia Pacakolonial. Jurnal Gramatika. Voleme 3.i1 (89-100)

Foucault, Michel. (2009). Pengetahuan \& Metode: Karya-karya Penting Foucault. Penejemah Arief. Yogyakarta: Jalasutra.

Hidayati, Wiwik. (2008). Pengaruh Dominasi Penjajah atas Subaltern dalam Novel Cantik Itu Luka Karya Eka Kurniawan; Analisis Berdasarkan Pendekadatan Poskolonialisme (Sripksi). Semarang: Fakultas Sastra Universitas Diponegoro.

Marshall, Catherine \& Gretchen B. Rossman. (2006). Designing Qualitative Research. London: Sage Publications.
Najid, Muhammad. (2009). Mengenal Apresiasi Prosa Fiksi. Surabaya: University Press.

Ratna, Nyoman Kutha. (2008). Poskolonialisme Indonesia. Yogyakarta: Pustaka Pelajar

Toer, Pramoedya Ananta. (2015). Arok Dedes. Jakarta: Lentera Dipantara

Saputri, Nur Fauziah. (2019). Dominasi Penjajah Terhadap Subaltern Dalam Novel Larasati Karya Pramoedya Ananta Toer (Suatu Pendekatan Poskolonial Gayatri C. Spivak ). Jurnal eprints. http://eprints.unm.ac.id/13984/ 